\title{
LA BECA DE RETORNO DE LA UNIVERSIDAD PERUANA CAYETANO HEREDIA
}

\begin{abstract}
Humberto Guerra ${ }^{1}$
\section{RESUMEN}

Desde hace muchas décadas los países en desarrollo sufrimos de la "fuga de cerebros". Los países industrializados han elevado sus barreras y han creado mecanismos para atraer a los profesionales extranjeros, con una agresiva actitud de captura de talentos, en el afán de ganar competitividad. Para menguar esa situación, la Universidad Peruana Cayetano Heredia ha creado su propia beca del retorno hace unos 12 años, repatriando a 12 científicos. El salario que los ha atraído suma en total US\$333 540 y ellos han logrado captar fondos para investigación de US\$ 9249828,42 en el mismo período, cifra que es 27 veces mayor a lo que invirtió en ellos la universidad. Han producido ocho artículos nacionales y 68 artículos internacionales, han preparado a nivel de tesis a 29 estudiantes de pregrado y a 20 de posgrado. Esta experiencia, todavía en evolución, representa un éxito capaz de ser emulado por otras universidades e instituciones de nuestros países.
\end{abstract}

Palabras clave: Investigadores; Migración internacional; Universidades; Perú (fuente: DeCS BIREME).

\section{RETURN SCHOLARSHIP OF THE UNIVERSIDAD PERUANA CAYETANO HEREDIA}

\begin{abstract}
Developing countries suffer from brain drain for many decades. Industrialized countries have raised their barriers against immigrants, but have created mechanisms to attract foreign professionals, with aggressive policies to capture talents, in an effort to increase their competitiveness. To mitigate the effects of the migration of scientists, the Universidad Peruana Cayetano Heredia has created its own "return scholarship" about 12 years ago, and has repatriated 12 scientists through it. The funds invested in attracting the scholars total U.S. \$333,540.00 and they have secured U.S. \$ 9'249,828.42 in research funds during the same period, a figure over 27 times higher. They have published 8 articles in national journals, 68 internationally, and trained 29 undergraduate and 20 graduate students as Thesis Tutors. Other universities and institutions of our countries can emulate this successful experience, which is still evolving.
\end{abstract}

Key words: Research personnel; Emigration and immigration; Universities; Peru (source: MeSH NLM).

\section{INTRODUCCIÓN}

Todos conocemos el fenómeno de la "fuga de cerebros" o fuga de talentos ${ }^{(1,2)}$. En estos días, puede observarse una suerte de cacería de talentos, cuando las sociedades poderosas y adelantadas buscan denodadamente garantizar su mayor desarrollo en medio de la gran competencia actual. Se busca la contratación de los científicos más destacados, con ofertas sumamente atractivas, entre ellas se cuenta el ofrecimiento de laboratorios ya montados, posibilidad de incluir a grupos de investigación establecidos, es decir a varias personas en la oportunidad, salarios especiales, privilegios para el traslado de familias y bienes, alojamientos, y otras ventajas $^{(3)}$.
Los países en vías de desarrollo que proveen algunos de los talentos que son ahora tan buscados, tienen poca capacidad de competir, a menos que establezcan oportunidades que sean atractivas para sus propios científicos que, usualmente, han salido a perfeccionarse al extranjero y se encuentran tentados de permanecer allí donde estudiaron ${ }^{(3,4)}$. Cuenta mucho en esta competencia tan desigual el deseo de los científicos de regresar a su propio país y dedicar su actividad a su propio pueblo. Es necesario estimular a los gobiernos a reconocer las grandes ventajas que trae el apostar por la ciencia y la tecnología y a actuar en consecuencia, procurando revertir la fuga de talentos con programas capaces de atraer y retener a los científicos formados que deseen contribuir al desarrollo de su país ${ }^{(5,6)}$.

1 Doctor en Medicina, Vicerrector de Investigación, Universidad Peruana Cayetano Heredia. Lima, Perú.

Recibido: 25-07-10 Aprobado: 04-08-10 


\section{¿CÓMO PERDEMOS CIENTÍFICOS Y OTROS PROFESIONALES?}

Es notorio que los países en desarrollo sufrimos desde hace décadas de la pérdida de nuestros profesionales y científicos hacia los países industrializados ${ }^{(7)}$. El mecanismo más frecuente es el de permanecer en el país donde logran estudios superiores, muchas veces en disciplinas muy poco o nada representadas en los países de origen. A veces, la precariedad de la permanencia es motivo de considerable ansiedad.

Inicialmente, con el criterio de proteger las vacantes laborales para sus propios ciudadanos, los países receptores y algunas organizaciones internacionales han creado mecanismos de repatriación, que no han sido muy efectivos. Se han desarrollado tensiones entre las empresas o universidades, hospitales, etc., que encuentran que los profesionales y científicos extranjeros son deseables por su buena preparación, competencia $\mathrm{y}$, evidentemente, sus menores pretensiones salariales, y los organismos de migración de los Estados, que usan diversos métodos o estrategias, siendo lo más corriente la deportación a costo del deportado, pero llegando al extremo de la expulsión forzada de quienes permanecen incluso tiempos cortos más allá de los permisos con plazos estrictos concedidos por las visas que ostentan.

Algunos programas internacionales de formación de profesionales condicionan el goce de las becas que propician a un retorno planificado para la fecha de terminación de la beca. Varios programas reservan el dinero del retorno como parte de la misma beca, concediendo esos fondos con solamente ese propósito. Existen los programas que entregan a sus becarios exitosos fondos de repatriación, incluyendo dinero para la instalación personal o familiar, y hasta para la implementación de un laboratorio.

Algunos países han establecido programas para la repatriación de extranjeros radicados que lo deseen, mediante un sistema que revisa las candidaturas de personas que quieren regresar a sus países y las oportunidades de trabajo provenientes de estos. El sistema recompensa al retornante con fondos de instalación. El sistema de concordar ofertas y demandas individualmente, o matching, existe también como parte de las tareas de la Organización Internacional de las Migraciones (OIM). Es un hecho que la migración de talentos es un fenómeno de envergadura global y que contribuye no poco a la famosa globalización en marcha ${ }^{(1)}$.

Existe actualmente otra situación. Desde hace algún tiempo puede observarse una actitud más agresiva de "captura selectiva de talentos", que se ha extendido a los científicos, a partir de las más notorias "cacerías", para contar con los deportistas profesionales más famosos o con los hombres de negocios, gerentes, barones de las finanzas más exitosos en las empresas, privadas o estatales. Las cacerías adoptan diversas formas, y existen empresas reclutadoras, llamadas expresivamente headhunters o "cazatalentos" que se dedican a buscar y contratar personas según las especialidades de sus clientes. Los que quieren ser "capturados" inscriben sus candidaturas, esperando ser llamados, en un sistema similar a los concursos para ocupar plazas en las instituciones.

Se busca la contratación de los científicos más destacados, con diversas ofertas sumamente atractivas, entre ellas se cuenta el ofrecimiento de laboratorios ya montados, la posibilidad de incluir a sus grupos de investigación establecidos, es decir a varias personas en la misma oportunidad, salarios especiales, privilegios para el traslado de familias y bienes, alojamientos ya pagados, y otras ventajas. Los países en vías de desarrollo que proveen algunos de los talentos que son ahora tan buscados tienen poca capacidad de competir, a menos que establezcan oportunidades que sean atractivas para sus propios científicos que usualmente han salido a perfeccionarse al extranjero y se encuentran tentados de permanecer allí donde estudiaron, o a regresar después de un breve período en su propio país. No hay escasez de candidatos a quedarse en el extranjero, ya que los adiestramientos largos, los períodos posdoctorales, los viajes prolongados con fines de investigación, pueden convertirse en buenas oportunidades para quienes desean hacer una "defección".

Es indudable que la llamada "fuga de cerebros" merma la capacidad de los países "donantes", que usualmente carecen de una capacidad científico-tecnológica apreciable, y se han generado mecanismos para revertir ese flujo ${ }^{(5-7)}$. Entre ellos están los compromisos de retorno, la pérdida del reconocimiento de años de servicio al considerarse la jubilación, la posibilidad de tener que devolver el dinero del adiestramiento, y seguramente otros más.

Una vez que un investigador forma parte de una organización en el extranjero la tendencia es a que permanezca progresando en su profesión, pero muchas veces continúa pensando en su retorno. Ese retorno puede ser pospuesto muchas veces, cada vez justificadamente. "Nos quedaremos hasta que tenga suficiente dinero para instalarnos como se debe"; "Hasta que los chicos terminen aquí su primaria", y más adelante, "Hasta que los chicos terminen aquí su secundaria", como los "chicos" han hecho su vida en el extranjero, "Hasta que no nos necesiten tanto" y después “¿Cómo vamos a dejar a los nietos?”. 
Algunos científicos y médicos instalados en el extranjero están muy motivados y contribuyen notablemente a las actividades de su universidad de origen o a la profesión con sus colegas, sociedades científicas, sus pueblos de origen, o de alguna otra forma. Algunos se convierten en docentes migratorios o investigadores colaboradores de sus instituciones nacionales. Todas esas modalidades, por supuesto, son beneficiosas y nuestras instituciones y los jóvenes estudiantes y profesionales deben obtener el mayor provecho posible de ellas.

\section{¿EN QUÉ FORMA SE PUEDE FAVORECER EL RETORNO DE LOS CIENTÍFICOS?}

Cuenta mucho en esta desigual competencia por atraer al capital humano a su país de origen el deseo de los científicos de regresar y dedicar su actividad a sus propios connacionales. Es necesario estimular a los gobiernos a reconocer las grandes ventajas que trae el apostar por la ciencia y la tecnología para la innovación, la competitividad y el desarrollo. Convencidos quienes tienen la capacidad de decisión, deben actuar en consecuencia, procurando revertir la fuga de talentos con programas capaces de contrapesar el atractivo de las facilidades y ventajas de que gozan en el extranjero y de retener a los científicos formados que deseen contribuir al desarrollo de su país.

Existen en diversos países, incluso de nuestro continente, programas nacionales del tipo de las Becas del Retorno ${ }^{(8,9)}$. Los científicos que se acogen a ellos son recibidos en diferentes laboratorios en ciudades de importancia en sus países, y se les da un lugar de distinción.

Quizás el Programa Raíces, o R@íces del Ministerio de Ciencia, Tecnología e Innovación Productiva de la República Argentina es el que se ha hecho más conocido. R@íces significa Red de Argentinos Investigadores y Científicos en el Exterior, y se inició en 2003. Al consultar la página web encontramos que han sido repatriados en este programa, que complementa el programa similar de CONICET, 768 científicos argentinos. Los subsidios cubren el costo del traslado, donativos privados 0 estatales para cubrir salarios hasta que se asegura el trabajo, y fondos para iniciar investigaciones ${ }^{(10)}$.

En 2004, había 59 mil investigadores en Argentina, y el número subió a 79 mil en 2008; $81 \%$ están en instituciones estatales (11). La experiencia es exitosa y aspiramos a consolidarla, así como a lograr que la Argentina sea un país atractivo para los científicos de todo el mundo. Desde el momento en que la educación es gratuita en el país, la formación de los científicos constituye una inversión de la sociedad en su conjunto que es millonaria e identificable. Es una obligación del Estado recuperar esa inversión para beneficio del país, afirma Lino Barañao, ministro de Ciencia, Tecnología e Innovación Productiva ${ }^{(12)}$.

El Perú ha inaugurado en 2009 la Beca de Reinserción, modelada en las mismas líneas, que está a cargo del Consejo Nacional de Ciencia y Tecnología, pero resulta todavía bastante modesto ${ }^{(13)}$. Un becario de reinserción está ya activo en el Instituto Nacional de Salud, organismo de investigación del Ministerio de Salud. Este programa debe crecer y hacerse más significativo.

La Beca del Retorno ya es una institución en la Universidad Peruana Cayetano Heredia (UPCH), que se ha atrevido a establecerla, como una de varias iniciativas destinadas a promover la investigación. Esas iniciativas aparecen en la página Web institucional (http://www. upch.edu.pe/vrinve/fconcursoa.asp), como Apoyo al Investigador, e incluyen fondos concursables, estímulo a las publicaciones, régimen de subvenciones para la asistencia a reuniones científicas, y así sucesivamente.

La Beca de Retorno de la UPCH consiste en el esfuerzo de la universidad en repatriar a científicos jóvenes con el grado de Doctor (Ph.D. o Dr.Sc.), con una trayectoria meritoria y que deseen desarrollar su futuro en nuestra universidad. Los resultados de este programa, que se desarrolla hasta ahora, de acuerdo con nuestras posibilidades, son palpables en la docena de científicos que compitieron y fueron seleccionados para obtener el goce de una remuneración mayor al promedio de docentes ordinarios de la universidad durante dos años y comprometerse a cumplir las exigencias del programa.

La historia se remonta a solamente diez años. El programa, que ahora está a cargo de fondos del Vicerrectorado de Investigación, se inició en realidad con el financiamiento de la Fundación Cristina e Ismael Cobián Elmore, que se dedica a apoyar a la Facultad de Ciencias y Filosofía "Alberto Cazorla Talleri" de la UPCH. Los becarios favorecidos, solo dos, previos al año 2000, habían pertenecido a la misma Facultad y regresaron a ella. Los fondos de la Fundación también han permitido auxiliar en la financiación de algunos becarios, en ciertas ocasiones. Esto ha introducido variaciones en el monto de los fondos recibidos por los becarios, según las épocas.

En 2003 se instituyó oficialmente el actual programa de Beca del Retorno, con fondos del Vicerrectorado de Investigación. Los candidatos son presentados por una Facultad y, de ser seleccionados gozan de un fondo salarial de retorno de US\$ 42 000. La Facultad responsable del becario asume el salario a partir del tercer año, incorporándolo a su plana docente. 
Los compromisos del becario y de la Facultad son sumamente importantes. La candidatura implica una adscripción del futuro becario a la Facultad correspondiente, con un plan de trabajo y la decisión de dedicar su actividad a la investigación por dos años, complementada por docencia especializada por hasta $10 \%$ del tiempo. Entre las actividades de investigación se encuentra la generación de proyectos de investigación, que deben permitir en algún momento el autosostenimiento parcial del becario; la dedicación a un área de conocimiento, generando un grupo de trabajo con estudiantes, graduados jóvenes y otros colaboradores, dentro y fuera de la universidad; el grupo publicará artículos y trabajará las disciplinas correspondientes, obteniendo fondos para su sostenimiento y desarrollo futuros como un polo de actividad científica.

El marco que acabamos de esbozar ha permitido atraer y retener a 11 de los 12 doctores escogidos. Inevitablemente, aparecen enormes variaciones en el desempeño de los becarios, según su personalidad y grado de inquietud académica y científica. Por ello, para no dar lugar a comparaciones, daré solamente apreciaciones globales.

Debemos indicar si la apuesta por la ciencia, que como país y como institución debemos realizar, dio resultado a este nivel prácticamente individual. Los 12 becarios han significado una inversión total de US\$ 333540 , considerando hasta los dos presentes, que todavía no completan su ciclo de dos años. En dinero, los fondos de investigación que han traído a la universidad representan US\$ 9249 828,42, una cifra más de 27 veces superior. En publicaciones, han producido ocho artículos nacionales y 68 artículos internacionales. En su actividad académica, han preparado, a nivel de tesis, a 29 estudiantes de pregrado y a 20 de postgrado.

\section{DISCUSIÓN Y CONCLUSIONES DE UNA HISTORIA INCONCLUSA}

La apuesta que ha realizado la Universidad Peruana Cayetano Heredia en este programa ha sido exitosa, aun si contamos solamente estos cortos años desde 1998; el fruto de este esfuerzo se debe notar en los años futuros, en que los becarios, entre los cuales ya se cuentan unos pocos que están en cargos directivos de las Facultades y de la Universidad, sigan rodeándose de nuevos científicos y multipliquen su actividad. Les esperan los años de madurez, que esperamos sean aun más fructíferos que los de su evidente juventud. Esperamos también mucho de los becarios del retorno futuros, que probablemente nos lleven por derroteros todavía no recorridos y serán capaces de ayudarnos mucho en el compromiso de crear una sociedad peruana mejor y más justa, a establecerse a través de la prosperidad del país y de todos los peruanos.

\section{AGRADECIMIENTOS}

A la Dra. Fabiola León Velarde, Rectora de la UPCH, impulsora de la Beca del Retorno oficial; Sra. Gabriela Sobarzo, Srta. Ursula Reyes, de la Dirección de Investigación, Ciencia y Tecnología, UPCH, quienes recopilaron la información. Al Dr. Percy Mayta-Tristán por la bibliografía sugerida.

\section{Conflictos de Interés}

El autor es propulsor de la beca de retorno de la UPCH.

\section{REFERENCIAS BIBLIOGRÁFICAS}

1. Sotomayor R. Globalización y la responsabilidad de los países en desarrollo: el caso de la migración de los profesionales de la salud. Rev Peru Med Exp Salud Publica. 2007;24(3):300-6.

2. Ioannidis JP. Global estimates of high-level brain drain and deficit. FASEB J. 2004;18(9):936-39.

3. Biene $\mathbf{M}$, Docquier $\mathbf{F}$, Rapoport $\mathbf{H}$. Brain drain and human capital formation in developing countries: winners and losers. Econ J. 2008; 118(528): 631-52.

4. Garcia PJ, Curioso WH. Strategies for aspiring biomedical researchers in resource-limited environments. PLoS Negl Trop Dis. 2008;2(8):e274.

5. Pupfer L, Hofman K, Jarawan R, McDermott J, Bridbord K. Strategies to discourage brain drain. Bull World Health Organ. 2004;82(8):616-23.

6. Saravia NG, Miranda JF. Plumbing the brain drain. Bull World Health Organ. 2004;82(8):608-15.

7. Dodani S, LaPorte RE. Brain drain from developing countries: how can brain drain be converted into wisdom gain? J R Soc Med. 2005;98(11):487-91.

8. Luchillo L. Migración de retorno: el caso argentino. Buenos Aires: Centro de Estudios sobre Ciencia, Desarrollo y Educación Superior; 2007.

9. Thorn K, Holm-Nielsen LB. International mobility of researchers and scientists. Policy options for turning a drain into a gain. Helsinski: UNU-WIDER; 2006.

10. Argentina, Ministerio de Ciencia, Tecnología e Innovación Productiva. Programa RAICES: una política de estado. Buenos Aires: MINCYT; 2010.

11. Belluscio A. Argentina smooths the path for returnees. Nature. 2010;466:519.

12. Fernández $\mathbf{N}$. Un plan que trajo de vuelta al país a más de 700 científicos. Diario Clarín. 2010; 27 junio. Suplemento económico.

13. Consejo Nacional de Ciencia, Tecnología e Innovación Tecnológica. Reglamento del concurso de becas de reinserción. Lima: CONCYTEC; 2009.

Correspondencia: Dr. Humberto Guerra

Dirección: Av. Honorio Delgado 430, Lima 31, Perú.

Teléfono: (511) 319-0028

Correo electrónico: humberto.guerra@upch.pe 